\title{
Study on Development of Sports Tourism in Xiang Xi Ancient Villages in“Internet Plus"era
}

\author{
Lizhong Wen ${ }^{1, a}$ and Yanxia Tang ${ }^{2, b}$ \\ ${ }^{1}$ College of Sports Science,Jishou Uniwersity,Renmin South Road 120,Jishou City Hunan \\ Province,China \\ awenlizhong1107@163,.com, b344342371@
}

\begin{abstract}
Keywords: "Internet plus"; Xiang Xi; ancient village; sports tourismT
Abstract. This is an era of rapid development.Because of Internet technology, the speed of the various information transmission quickens, which greatly changes people's traditional ideas. Such a change is a great opportunity of development, so government should seize this opportunity and choose the correct policy to realize ]sustainable development.Xiangxi area is in the northwest Hu Nan, locating at the junction of four provinces: Gui Zhou, Chong Ging, $\mathrm{Hu} \mathrm{Nan}$ and $\mathrm{Hu}$ Bei, where accumulates years of history and deep culture and exists superb natural scenery. There are many ancient villages and plentiful sport tourism resources in Xiang Xi. This paper analyzes the development of sports tourism in ancient Xiang $\mathrm{Xi}$ villages, and considering the nowadays environment"Internet plus", puts forward some measures and suggestions for the development of sports tourism in Xiang $\mathrm{Xi}$ ancient village so as to provide some reference for any relevant departments.
\end{abstract}

\section{Introduction}

The words "Internet plus" era was mentioned again by the premier Li Keqiang in 2015 government work report. Until now, "Internet plus" rise to the national level in China, marking the "Internet plus" has been integrated into people's lives. "Internet plus" era plays a guiding role in public life, way of production, industry trend, laws and regulations, national policy. It can be said that the "Internet plus" as a core of ecology, plays a very positive role on a variety of related factors . For this reason, and with favorable conditions under the era of "Internet plus", it the industry of sports tourism in Xiang Xi ancient villages can upgrade towards the low-carbon consuming, sustainable circular economic development mode gradually .

\section{Sports Tourism in Xiang Xi Ancient Villages}

Sports tourism is a new tourism product in China. It is a way of tourism based on sports tourism resources.It not only has its essential function-- strengthening physical and mental fitness, but also reflects a colorful tourism, the harmony between man and society and human and nature, and the comprehensive development of people. Sports tourism consumption has became an important part of economic growth. It has become one of the most important indicators of national economic growth and an indispensable part in people's daily work and study. In fact, the sports tourism can be seen as a branch of the tourism industry. But this branch has its own specialization and particularity, so it can not be separated from sports participation, organization and guidance

Xiang Xi area, broad and in jurisdiction over7 counties and 1 city, its land area of 15 thousand and 500 square kilometers, is a typical "aged, minority, bordering, mountainous, poor" area. It is the pilot area for country's western development, Wu Ling Mountain Regional Area Development and poverty alleviation project. It is the only minority autonomous prefecture in Hunan province, and the main battlefields of Xiang Xi area development and poverty alleviation. Xiang Xi district exists 43 minorities, and its main ethnic minorities are Tujia, Miao minorities, forming the special multi-minorities regional culture. There are rich folk customs, folk arts and non-material cultural heritage. But Xiang xi area is relatively poor and the level of poverty is wide,so people's living 
standard is relatively low. In this case, relying on the sports resources, the development of sports tourism industry is a good way to ensure the sustainable economy development in Xiang Xi.

\section{Tourism Development Situation in Xiang Xi Ancient Villages}

From the perspective of macrography, the development of the sports tourism in Xiang Xi ancient villages is relatively optimistic because of favorable national policies,people's favor for sports tourism industry and the rich culture and sport resources. However, in practice because of these following problems, the quality and speed of the development of sports tourism are not satisfactory in Xiang Xi.

Sports tourism projects are close in space. Two tigers fight, there must be an injury. It is the taboo of industrial development that two similar projects are close in space, the same is for the development of tourism in Xiang Xi ancient ethic villages. Because of imperfect infrastructure and outdated traditional ideas, similar even same tourism projects exists relatively close in Xiang Xi.Although similar projects does not want to compete with each other,people will compare unconsciously, which will lead to one of the spots suffers loses, and in the course of time will limit the overall development of village sports tourism in Xiang Xi.

Development of Ethic Sports Tourism is low-level, often repeated .Because Residents in Xiang $\mathrm{Xi}$ ancient villages are not fully keep up with the trend of the times, and at the same time their infrastructure is not surrounded,so it is hard for local people to accept the advanced ideas emerging in the outside world and keep up with the speed of information transmission. In the development of ethnic sports resources in ancient village, residents often imitate each other, so the projects involving in the development of ethic sport resources usually are similar. This often appears the "thin field no tillage, plowing open everyone fight" phenomenon. The impact for the development progress and advance of ethnic sports tourism in Xiang $\mathrm{Xi}$ ancient village is very unfavorable.

The utilization rate of ethic sports resources is low, and its products are outdated. Although the culture of ethic sports in Xiang Xi varied, in the stage of development, these new projects are always "new bottled wine" and "a superficial reform" without innovation. For example, some major annual meeting like the annual autumn harvest festival and April eight, other tourist attractions also have similar festivals, so ethnic sports in Xiang Xi ancient villages are unattractive for many visitors. At the same time only Baishou dance, drum dance of Miao, Tujia Maogusi dance etc,these sports culture resources are displayed before visitors, and these performance can be traced back to a very long time ago, so the tourism products have been lagged behind the times. This due to the low-level of utilization rate of ethic sports resources.It is urgent to solve the problem.Improperly Marketing and High commercialization for Some Sports Tourism Project.

Some Sports Tourism Projects Market Improperly and are too commercialized. The wide spread of poverty in Xiang Xi can not be ignored, and the development of ethnic sports tourism in the ancient villages also is imperative. But some parts of the project market wrongly in development. These projects just are not the tool to promote special and precious ethic culture and the harmony human and nature, but tool of money-making simply. They are too much commercialized, even become vulgar and pseudo arts. This caused resentment for Xiang Xi ethnic sports tourism ,if this feeling spreads from people to people, the impact on ethnic sports tourism in Xiang Xi ancient villages will be fatal.

Local people's enthusiasm and participation are not fully aroused. The Base of ethnic sports tourism in Xiang $\mathrm{Xi}$ ancient villages is the unique culture formed by people through long time.The cultural which is formed by the people needs to be rooted in the people. However, development of some ancient villages ignore local people. Because of various interests intertwined together,the enthusiasm and participation of surrounding people are greatly reduced, so the performance of the ethic sports is gorgeous in appearance but not touching and attractive in essence. In the course of time, ethnic sports tourism in Xiang Xi ancient villages will lost vitality and even will be destroyed. 


\section{The upgrade of sport tourism in Xiang XI ancient villages under the era "Internet plus"}

Considering current domestic environment, the condition of sports tourism development in the ancient villages in the era of "Internet Plus" is not mature. It is still in the exploratory stage. The market is small, and its service quality, price and other aspects are uneven. But this field is still the best direction for the development of Xiang Xi region.To achieve the transformation and upgrading of sports tourism in Xiang Xi, ancient villages should make use of this era. So in the future from sports resources and users tow aspects, the real change should be realized so as to the sports service is more profitable and accessible. "sports resources " are available to all users.

Scientific Planning in the era of "Internet plus". The efficiency of resource utilization can be improved if The ethnic sports tourism resources in Xiang $\mathrm{Xi}$ ancient villages are developed scientifically and integrally. The enterprise which have similar folk activities can gather together to discuss the direction of development in the future. If people's thoughts are respected and related apartments plan scientifically and systematically, these tourist spots can develop harmoniously. These problems like low utilization and repetition of ethic sport tourist can be avoided.

Establishing Related Regulations in the era of "Internet plus". The basic guarantee of the ethnic sports tourism development in Xiang Xi ancient villages is system, so the appropriate market system must be established. All project should return back to the original aim of the ethic ancient tourist development of Xiang Xi ancient villages and reduce vulgarization to attract more people. At the same time, the market has to play a decisive role in allocating resources. Tourist company should compete with each other so the less competitive companies will be sifted out and the productivity and quality of the development of ethic sport tourism in Xiang Xi ancient villages improve. In addition, the government should also play the important role of macro-control accordingly, so the tourist price is reasonable. The sport resources really involved into people's life.

Achieving innovative development in the era of "Internet plus". Sports resources should be re-examined to achieve the transformation and upgrading of the ethnic sports tourism in Xiang Xi ancient villages in the era of "Internet plus". The undiscovered resources should be fully utilized.We should consider the current domestic situation and people's ideas and pursuits and cater to the market need for ethnic sports culture. We must accelerate the speed of information transformation and follow the trend of the times. At the same time, the tourist spots will attract more visitors by bold innovation and rich content and new forms to achieve the optimal allocation of ethnic sports tourism resources.A relatively complete system of products should be established so as to upgrade the industry and promote the economic development in Xiang $\mathrm{Xi}$ ancient villages.

Mobilizing the Enthusiasm of Local People in the era of "Internet plus". The fundamental purpose of the transformation and upgrading of sport tourism in Xiang $\mathrm{Xi}$ ancient villages is to achieve economic development, improve the life quality of local people, and meet the needs of people's life. So sports tourism in ancient villages should closely connect with the local people. Local people will know about and be involved in the development of sport tourism in ancient villages by massive and long-term propaganda and education.People's enthusiasm and participation will be really stimulated if they take part in sport and make influences. Xiang xi people will know their role of master,so that Xiangxi people will understand and support the development of sports tourism in the ancient village and volunteer to work for it. The vigorous vitality of the ethic sport tourism can be fully shown and the transformation and upgrading can be achieved in the area of "Internet plus".

Focusing on the Development Form of Sports Tourism in the era of "Internet Plus" . In the era of "Internet plus", the development pattern must not fall into the erroneous thinking zone, that is ,to attract visitors' attention projects become "difficult, bizarre, strange". Although this wrong pattern will lead to a certain boom in the short term, but in the long term ethic sport tourism will lose market, resulting in negative effects. So the form of sports tourism transformation and upgrading in Xiang Xi ancient villages should be focused in the era of "Internet plus". 


\section{Summary}

Today is new era. Nowadays the green and sustainable development is the appropriate pattern of development and an ideal way of development in people's mind. So various new tools should be fully used if we want to make progress in Xiang Xi. Changing the development mode of ethic sport tourism in Xiang $\mathrm{Xi}$ ancient villages and achieving the transformation and upgrading of the economic development pattern,local people will make effective progress in economy and culture, etc by more scientific, more green, more sustainable way.

\section{Acknowledgment}

Sports science society in hunan province (2016XH036), Jishou university young talent scientific research projects $(16 \mathrm{SKB} 007)$

\section{References}

[1] $\mathrm{Yu}$ Wanbin. Low carbon era of ancient village sports tourism development strategy research in China [J]. Journal of hubei academy of social sciences, 2013.81 83.

[2] Zhao Jinling. Theory and empirical studies of high-end sports tourism in China [D]. Fujian normal university, 2013.

[3] ya-ting he. Based on the ancient village tourism mountain villages and towns reform research [D]. Chongqing university, 2009.

[4] TaoPing. Circulation economic development research - ancient village sports tourism based on low carbon ecological perspective [J]. Journal of shenyang sports institute, 2014.64 67.

[5] guo-rong tang. The influence factor of development of ancient village sports tourism research [J]. Journal of jintian, 2013.10

[6] Liu Shengbing. Sports tourism and the combination of the ancient village tourism development countermeasure analysis [J]. Journal of China commerce and trade, 2012.173 174+177. 